\title{
EKSPLORASI KONSEP ETNOMATEMATIKA PADA ALAT PERTANIAN TRADISIONAL SUKU BUGIS DI KABUPATEN PINRANG
}

\author{
Ady Akbar* \\ *Program Studi Pendidikan Matematika, Fakultas Keguruan dan \\ Ilmu Pendidikan, Universitas Sawerigading Makassar
}

Email korespondensi : adyakbar09@gmail.com

\begin{abstract}
Abstrak
Penelitian ini bertujuan untuk mengeksplorasi dan menganalisis konsep etnomatematika yang terkandung pada alat-alat pertanian tradisional suku Bugis di Kabupaten Pinrang. Metode yang digunakan dalam penelitian ini adalah metode eksploratif-deskriptif melalui pendekatan etnografi yang bertujuan untuk menggambarkan, menjelaskan dan menganalisis konsep-konsep matematika pada alat pertanian tradisional suku Bugis. Teknik pengumpulan data dilakukan melalui kajian literatur, observasi, wawancara, dan dokumentasi. Teknik analisis data yang digunakan adalah interactive model, yaitu reduksi data (data reduction), penyajian data (display data), dan penarikan kesimpulan (verifikasi). Pemeriksaan keabsahan data dilakukan dengan triangulasi sumber. Hasil penelitian menunjukkan bahwa terdapat konsep etnomatematika dalam alat-alat pertanian tradisional suku Bugis di Kabupaten Pinrang. Konsep etnomatematika yang dimaksud adalah: (1) Konsep bidang datar layang-layang terkandung dalam alat pertanian Teda', (2) Konsep bidang datar persegi panjang terkandung dalam alat pertanian Passampa', dan (3) Konsep bidang datar lingkaran terkandung dalam alat pertanian Pattapi. Konsep etnomatematika yang terkandung dalam sejumlah alat tradisional suku Bugis memiliki relevansi dengan konten pembelajaran matematika pada pendidikan formal sekolah dasar.
\end{abstract}

10.26418/pipt.2021.14

Kata kunci: Etnomatematika, Alat Pertanian, Suku Bugis

\section{PENDAHULUAN}

Matematika adalah salah satu mata pelajaran terpenting di sekolah dalam masyarakat modern. Matematika sebagai salah satu mata pelajaran yang diajarkan di bangku sekolah memiliki peranan yang sangat penting karena dapat meningkatkan pengetahuan siswa dalam berpikir secara logis, rasional, kritis, cermat, efektif, dan efisien (Akbar \& Haidar, 2019). Oleh karena itu, matematika menjadi aspek fundamental dan kemestian bagi manusia berpengetahuan di dunia modern saat ini. Matematika sebagai salah satu mata pelajaran yang diajarkan di bangku sekolah memiliki peranan yang sangat penting karena dapat meningkatkan pengetahuan siswa dalam berpikir secara logis, rasional, kritis, cermat, efektif, dan efisien. Dalam Permendiknas No. 22 tahun 2006 disebutkan bahwa tujuan mata pelajaran matematika di sekolah adalah agar siswa memiliki kemampuan memahami konsep, menggunakan penalaran, memecahkan masalah, mengkomunikasikan gagasan, dan memiliki sikap menghargai kegunaan matematika dalam kehidupan sehari-hari.

Meskipun keberadaan matematika sangat penting, namun pada realitasnya banyak siswa yang gagal belajar matematika dan bahkan menganggap matematika sebagai pelajaran yang asing. Bishop dalam Adam (2004) mengatakan bahwa kondisi ini disebabkan karena matematika di ruangruang kelas sering dipisahkan dengan kebudayaan siswa yang seharusnya dapat menjadi objek pembelajaran matematika. Oleh karena itu, guru harus memperhatikan faktor budaya dalam pembelajaran matematika.

Matematika dan kebudayaan merupakan dua aspek yang memiliki hubungan yang kuat (Barta \& Shockey, 2006). Pada satu sisi, sebagaimana diutarakan oleh Clifford Gertz dalam Latif (2020), kebudayaan merupakan keseluruhan cara hidup dari sebuah masyarakat. Cara hidup ini meliputi hubungan antara manusia, nilai, praktik, simbol, hingga cara 
menerapkan ide-ide dan konsep-konsep matematika dalam aktivitas sehari-hari. Entremont (2015) mengatakan bahwa matematika merupakan hasil konstruksi kebudayaan dan merupakan komponen integral dari semua konteks budaya.

Keterlibatan matematika dalam kebudayaan masyarakat tertentu bukanlah hal yang baru. Penetrasi dan pengaruh matematika dalam kehidupan masyarakat tidak hanya terjadi pada kehidupan manusia modern di mana konsep matematika banyak digunakan pada perangkat teknologi yang menjadi kebutuhan manusia modern sekarang ini, namun matematika telah banyak diterapkan oleh masyarakat tradisional maupun masyarakat adat sejak dahulu. Misalnya masyarakat Toraja (Side et al., 2021), menggunakan sejumlah konsep geometri dan persamaan matematika dalam pembuatan rumah adat Tongkonan. Selain itu, juga sejumlah konsep-konsep geometri seperti bola, trapesium, dan persegi panjang pada sejumlah permainan tradisional anak pada masyarakat Poogalam Kabupaten Buton Selatan (Nurbianti, Fahinu, \& Kadir, 2019).

Studi tentang hubungan antara matematika dan kebudayaan disebut dengan istilah etnomatematika. Terminologi 'etnomatematika' dipopulerkan oleh D'Ambrosio pada tahun 1985 untuk menjelaskan konsep matematika yang diterapkan dalam budaya tertentu. D'Ambrosio (2001) sebagai tokoh yang mempopulerkan istilah ini menjelaskan bahwa etnomatematika adalah studi yang mempelajari bagaimana masyarakat mengembangkan teknik untuk menjelaskan dan memahami dunia mereka melalui penerapan ide dan konsep-konsep matematika.

Pada dasarnya, matematika merupakan bentuk dari kebudayaan. Dalam hal ini, matematika dipandang sebagai entitas yang telah terintegrasi dalam seluruh aspek kehidupan masyarakat. Pinxten dalam Sylviyani (2017) menyatakan bahwa pada hakekatnya, matematika merupakan teknologi simbolis yang tumbuh pada keterampilan atau aktivitas lingkungan yang bersifat budaya. Hal ini berarti pemahaman matematika seseorang dipengaruhi oleh latar budayanya karena yang mereka lakukan berdasarkan apa yang mereka lihat dan rasakan. Pendapat ini juga dikuatkan oleh Yanti, Widada, dan Syukur (2018) yang menjelaskan bahwa aktivitas-aktivitas matematika yang di dalamnya terjadi proses pengabstraksian dari pengalaman nyata dalam kehidupan sehari-hari ke dalam matematika atau sebaliknya, meliputi aktivitas mengelompokkan, berhitung, mengukur, merancang bangunan, atau alat, membuat pola, membilang, menentukan lokasi, bermain, menjelaskan dan sebagainya.

Menurut Harding-dekam (2017), etnomatematika adalah istilah yang diciptakan untuk menjelaskan bahwa setiap orang dapat menggunakan dan belajar matematika. Dengan demikian, penerapan etnomatematika sebagai suatu pendekatan pembelajaran merupakan cara lain untuk menyampaikan matematika secara lebih menarik. Jadi, dapat disimpulkan bahwa etnomatematika adalah matematika yang tumbuh dan berkembang serta dipengaruhi oleh budaya.

Argumen tersebut juga relevan dengan pendapat Rosa dan Orey (2003) yang mengatakan bahwa etnomatematika merupakan penerapan teknik dan ide matematika melalui aktivitas seperti menghitung, mengukur, atau menimbang untuk menyelesaikan masalah dan menciptakan dunia yang berarti. Dalam perspektif yang lebih luas, Orey dan Rosa (2006) memandang bahwa etnomatematika merupakan irisan dari bidang kajian antropologi budaya, matematika, dan pemodelan yang memiliki relevansi dalam aktivitas pedagogik. Hal ini berarti komponen kebudayaan memiliki peranan sekaligus pengaruh terhadap praktik pedagogi pembelajaran matematika di kelas. Selain itu, penerapan etnomatematika akan memudahkan siswa untuk mengembangkan pemahaman yang lebih dalam dan meningkatkan penyerapan konsep 
matematika formal yang dipelajari di sekolah (Rosa \& Orey, 2011).

Pengintegrasian aspek-aspek budaya dalam pembelajaran matematika akan mendorong pembelajaran matematika menjadi lebih bermakna. Kegagalan siswa dalam pembelajaran matematika disebabkan karena tidak hadirnya konteks budaya dalam pembelajaran matematika di kelas. Pandangan ini sesuai dengan pendapat Adam (2004) yang mengemukakan bahwa budaya masyarakat memiliki hubungan yang erat dengan praktik pedagogi dalam kelas. Hal ini disebabkan karena siswa datang ke sekolah dengan turut serta membawa sejumlah nilai, norma, dan konsep yang telah mereka peroleh dari lingkungan masyarakat.

Pada dasarnya, variabel budaya memiliki pengaruh yang kuat dalam proses aktivitas pedagogi di kelas. Variabel kebudayaan akan memudahkan siswa dalam proses memahami dan menafsirkan dunia mereka. Sederhananya, budaya mempengaruhi cara kita memperoleh dan menggunakan pengetahuan matematika kita sendiri. Penggunaan contoh-contoh konsep matematika yang disesuaikan dengan kebiasaan dan budaya siswa akan memudahkan siswa dalam proses pembelajaran matematika di kelas (Yanti, Widada, \& Syukur, 2018).

Pengintegrasian konteks budaya dalam pembelajaran matematika di kelas akan mendorong semangat siswa untuk mempelajari matematika. Selain itu, pengintegrasian objek-objek budaya dalam pembelajaran matematika akan meningkatkan kemampuan siswa untuk membuat koneksi yang berarti, dan memperdalam pemahaman matematika. Pada dasarnya, objek etnomatematika merupakan objek budaya yang mengandung konsep matematika pada suatu masyarakat tertentu. Objek etnomatematika tersebut dapat berupa permainan tradisional, kerajinan tradisional, artefak, dan aktivitas atau tindakan yang berwujud kebudayaan (Nurbianti, Fahinu, \& Kadir, 2019).
Salah satu objek sekaligus produk kebudayaan adalah alat pertanian tradisional suku Bugis. Bagi masyarakat suku Bugis, alat pertanian tradisional telah digunakan secara turun temurun dan merupakan suatu sistem teknologi produksi yang bersahaja. Fungsi dan manfaat dari alat tersebut bukan hanya dilihat dari segi fungsi praktis dan efisiensi kerjanya, melainkan juga dipakai sebagai simbol dari kepatuhan terhadap leluhur atau generasi sebelum mereka yang telah membuktikan daya dan hasil gunanya mulai waktu mengolah tanah, menanam, memelihara tanaman, memungut hasil, mengolah hasil produksi serta tata cara pendistribusiannya.

Eksplorasi etnomatematika pada alat pertanian tradisional suku Bugis belum pernah dikaji dan diteliti. Padahal, berdasarkan studi awal dan pengalaman serta pengamatan peneliti, diduga terdapat konsep-konsep matematika pada sejumlah alat pertanian tradisional yang digunakan oleh masyarakat Bugis. Oleh karena itu, hal ini menjadi motivasi bagi peneliti untuk melakukan kajian lebih jauh terkait etnomatematika pada alat-alat pertanian suku Bugis di Kabupaten Pinrang.

\section{METODE}

Penelitian ini merupakan penelitian eksploratif dengan pendekatan etnografi. Penelitian eksploratif dalam penelitian ini yaitu penelitian yang berupaya mengekplorasi atau mengidentifikasi karakteristik dan konsep matematika pada alat-alat pertanian tradisional suku Bugis di Kelurahan Tonyamang Kecamatan Patampanua Kabupaten Pinrang. Adapun pendekatan etnografi digunakan untuk menggambarkan, menjelaskan dan menganalisis konsep-konsep matematika yang terdapat pada alat pertanian tradisional suku Bugis.

Teknik pengumpulan data dilakukan dengan metode observasi, wawancara semi terstruktur, dan dokumentasi, yang kemudian dianalisis dan diidentifikasi konsep-konsep matematika yang ada di dalam alat pertanian tradisional masyarakat 
Bugis. Metode observasi dilakukan dengan melakukan pengamatan langsung terhadap bentuk alat pertanian suku Bugis di Kabupaten Pinrang. Adapun wawancara dilakukan dengan bertanya langsung kepada petani dan pembuat alat pertanian tradisional untuk mendapatkan informasi rinci terkait konsep matematika yang terkandung dalam alat pertanian suku Bugis. Sementara itu, metode dokumentasi dilakukan dengan cara mengumpulkan sejumlah data berupa rekaman hasil wawancara, gambar, dan video untuk keperluan analisis data.

Teknik analisis data yang digunakan adalah jenis interactive model yang mengklasifikasikan analisis data dalam tiga langkah berikut; (1) Reduksi data (Data Reduction), (2) Penyajian data (Display Data), (3) Penarikan kesimpulan (Verifikasi).

\section{HASIL DAN PEMBAHASAN}

Alat pertanian tradisional pada masyarakat Bugis di Kabupaten Pinrang antara lain Teda', Passampa', dan Pattapi. Bentuk etnomatematika yang terdapat pada alat pertanian ini memiliki kesamaan dan relevansi dengan konten matematika formal yang diajarkan pada tingkat sekolah dasar. Hasil-hasil eksplorasi etnomatematika alatalat pertanian tradisional suku Bugis di Pinrang memuat konsep-konsep matematika berupa: (a) Konsep layang layang; (b) Konsep lingkaran; (c) Persegi panjang.

Adapun alat-alat pertanian suku Bugis di Kabupaten Pinrang secara rinci dijelaskan sebagai berikut:

\section{Teda'}

Teda' merupakan alat-alat pemeliharaan tanaman yang berfungsi sebagai penyiang tanaman. Alat ini digunakan pada sawah yang berair. Dalam bahasa Indonesia, teda' dikenal dengan istilah pisau landak. Bahannya terbuat dari potongan lempeng besi plat atau seng tebal yang berbentuk layang-layang. Sisi teda' dibuat menjadi tajam dengan cara digosokkan pada batu asah, pecahan keramik atau dapat pula dikikir. Hal ini dimaksudkan agar pada saat digunakan, teda' dapat memotong rumput liar yang tumbuh di antara tanaman padi.

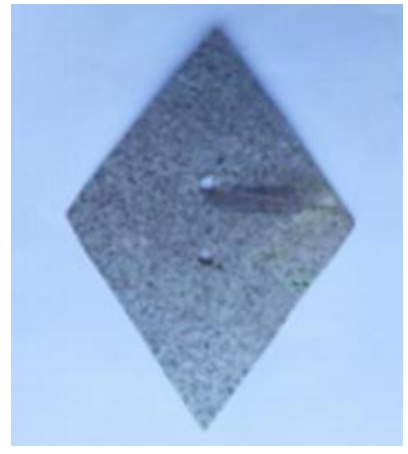

Gambar 1. Teda

Pada bagian permukaan atas, teda biasanya dihubungkan dengan bambu atau kayu yang berukuran panjang $100 \mathrm{~cm}$ hingga $130 \mathrm{~cm}$ yang berfungsi sebagai pegangan. Adapun cara penggunaan teda' adalah dilakukan dengan cara mendorong ke depan dan kemudian menarik ke belakang secara berulang-ulang di antara rumpun-rumpun padi sehingga tumbuhan liar yang tumbuh di antara rumpun padi dapat terpotong dengan alat ini.

\section{Passampa'}

Passampa' merupakan alat pertanian pasca panen yang berfungsi untuk merontokkan bulir padi dari batangnya. Di Indonesia, alat ini juga dikenal dengan istilah gebotan. Passampa' dibuat dari belahan bambu atau kayu yang disusun sedemikian sehingga membentuk bidang datar persegi panjang. Bidang datar ini kemudian dibuatkan penyangga sehingga permukaan bidang Passampa' dapat berdiri dengan kemiringan sekitar $40^{\circ}$.

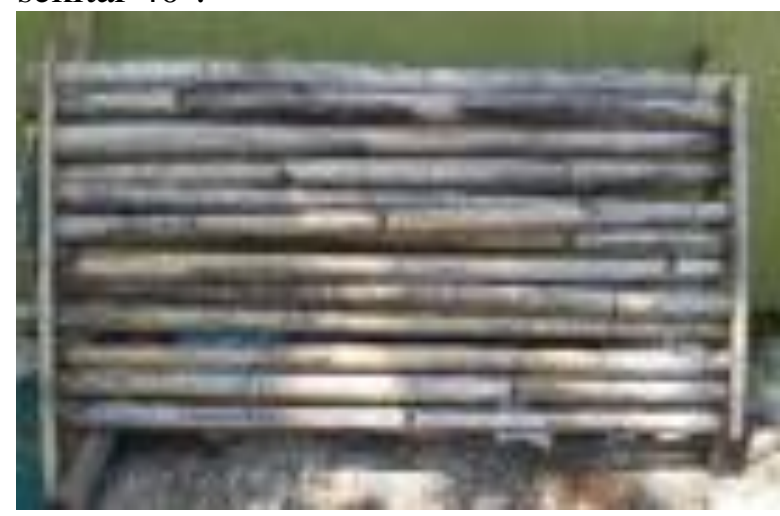

Gambar 2. Passampa'

Pada proses penggunaannya, batang padi dibanting pada permukaan Passampa' sehingga butiran-butiran padi akan terlepas dari batangnya. Proses ini dilakukan secara 
berulang-ulang agar butiran-butiran padi dapat terlepas secara merata. Proses Massampa' (kegiatan melakukan aktivitas merontokkan padi) umumnya dilakukan 3-7 hari setelah panen karena biji padi akan lebih mudah rontok dari batangnya jika didiamkan terlebih dahulu selama 3-7 hari dibanding jika langsung dirontokkan setelah selesai panen.

\section{Pattapi}

Pattapi merupakan alat pertanian pasca panen yang berfungsi untuk menapis atau membersihkan beras dari kulit gabah setelah melalui proses penggilingan. Pattapi dalam Bahasa Indonesia disebut dengan istilah nyiru atau tampah. Pattapi umumnya terbuat dari belahan kulit bambu yang kemudian dianyam berbentuk lingkaran. Diameter Pattapi biasanya berukuran 60-80 $\mathrm{cm}$.

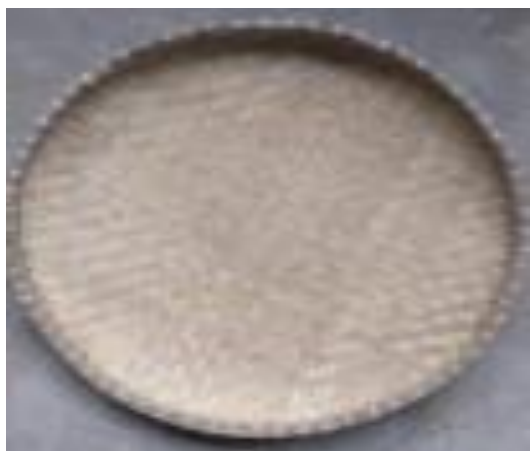

Gambar 3. Pattapi

Pada proses penggunaannya, beras yang akan ditapi atau dibersihkan diletakkan di atas permukaan Pattapi kemudian diayun ayunkan secara naik turun. Beras pada permukaan Pattapi juga sekali-kali digerakkan dengan arah memutar ke kiri dengan maksud agar kulit buah padi atau kotoran-kotoran lain yang berasal dari proses penumbukan dapat terpisah dari beras dan akan berkumpul menjadi satu sehingga mudah diambil.

\section{Konsep layang-layang pada bentuk Teda'}

Berdasarkan paparan pada hasil penelitian, dapat diketahui bahwa terdapat konsep bidang datar dalam alat pertanian tradisional Teda'. Bentuk Teda' pada gambar 1.a dapat dimodelkan secara geometri pada gambar 1.b seperti berikut.
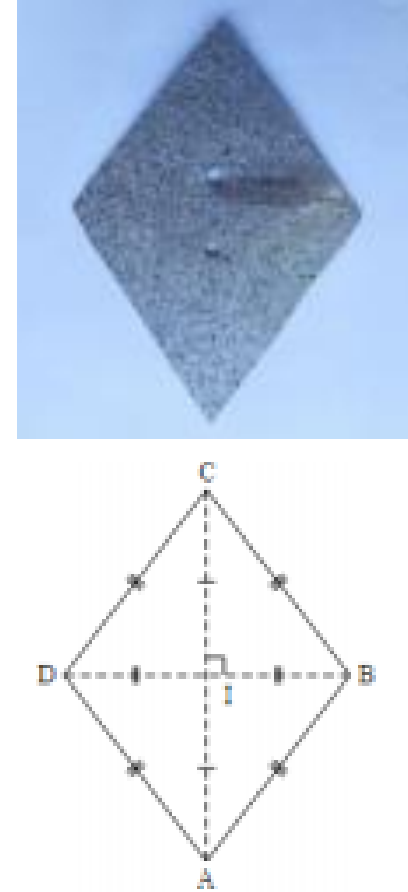

Gambar 1.a Alat pertanian Teda'

Gambar 1.b pemodelan bentuk permukaan Teda'

Dari Gambar 1.b, dapat diketahui bahwa pemodelan tersebut berbentuk bangun datar yaitu layang-layang. Selanjutnya, peneliti menganalisis konsep bangun datar layanglayang tersebut.

Berdasarkan analisis pada Gambar 1.a dan 1.b, diperoleh sifat-sifat layang-layang yang terdapat pada bentuk Teda' yaitu sebagai berikut:

a. Memiliki empat buah sisi yang sama panjang yaitu sisi $A B, B C$, $\mathrm{CD}$, dan DA

b. Memiliki dua pasang sudut yang berhadapan dan sama besar, yaitu $\angle \mathrm{ABC}=\angle \mathrm{ADC}$;

c. $\angle \mathrm{BAD}=\angle \mathrm{BCD}$

d. Memiliki dua buah diagonal yang saling berpotongan tegak lurus, yaitu diagonal AC dan diagonal BD.

\section{Konsep persegi panjang pada bentuk Passampa'}

Berdasarkan paparan pada hasil penelitian, dapat diketahui bahwa terdapat konsep bidang datar persegi dalam alat pertanian tradisional Passampa'. Bentuk Passampa' pada gambar 2.a dapat dimodelkan secara geometri pada gambar 2.b. 


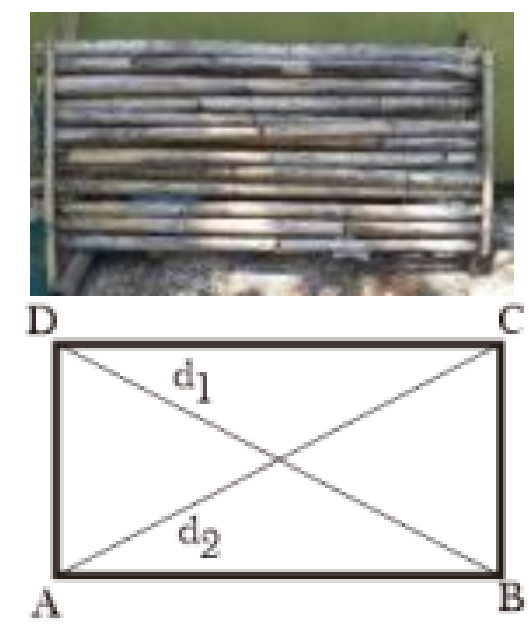

Gambar 2.a Alat pertanian Passampa' Gambar 2.b pemodelan bentuk permukaan Passampa'

Dari Gambar 2.b, dapat diketahui

bahwa pemodelan tersebut berbentuk bangun datar yaitu persegi panjang. Selanjutnya, peneliti menganalisis konsep bangun datar persegi panjang tersebut.

Berdasarkan analisis pada Gambar 2.a dan 2.b, diperoleh sifat-sifat persegi panjang yang terdapat pada bentuk Passampa' yaitu sebagai berikut:
a. memiliki 4 sisi
b. sisi yang berhadapan sama panjang dan sejajar, yaitu $A B=$ $\mathrm{CD}$ dan $\mathrm{AD}=$
c. $\mathrm{BC}$
d. kedua diagonalnya sama panjang dan saling berpotongan yatiu AC $=\mathrm{BD}$
e. memiliki 4 sudut yang sama besar yakni $90^{\circ}$

\section{Konsep lingkaran pada bentuk Pattapi}

Berdasarkan paparan pada hasil penelitian, dapat diketahui bahwa terdapat konsep bidang datar dalam alat pertanian tradisional Pattapi. Bentuk Pattapi pada gambar 3.a dapat dimodelkan secara geometri pada gambar 3.b berikut ini.

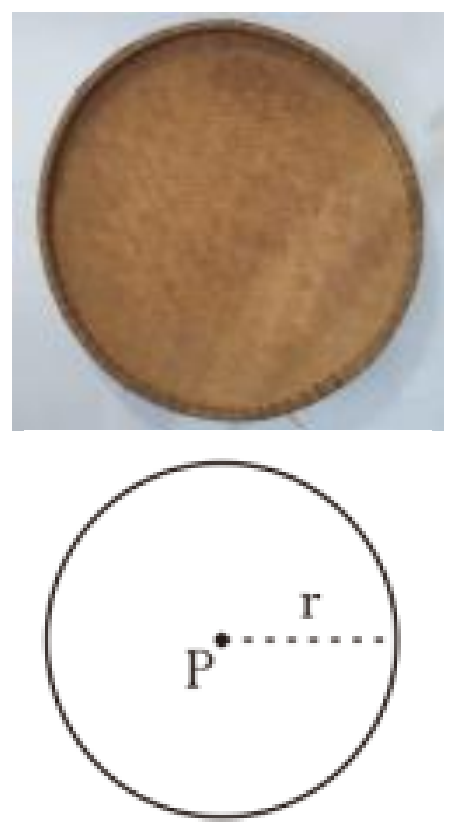

Gambar 3.a Alat Pertanian Pattapi

Gambar 3.b pemodelan bentuk permukaan Pattapi

Dari Gambar 3.b, dapat diketahui bahwa pemodelan tersebut berbentuk bangun datar yaitu lingkaran. Selanjutnya, peneliti menganalisis konsep bangun datar lingkaran tersebut.

Berdasarkan analisis pada Gambar 3.a dan 3.b, diperoleh sifat-sifat lingkaran yang terdapat pada bentuk Pattapi yaitu sebagai berikut:

a. hanya memiliki satu sisi

b. tidak mempunyai titik sudut

c. jarak antara titik pusat dengan sisi manapun selalu sama

\section{KESIMPULAN}

Berdasarkan uraian di atas maka dapat disimpulkan bahwa terdapat konsep etnomatematika dalam alat-alat pertanian tradisional suku Bugis di Kabupaten Pinrang. Konsep etnomatematika yang dimaksud adalah: (1) Konsep bidang datar layang-layang terkandung dalam alat pertanian Teda', (2) Konsep bidang datar persegi panjang terkandung dalam alat pertanian Passampa', dan (3) Konsep bidang datar lingkaran terkandung dalam alat pertanian Pattapi. Konsep etnomatematika yang terkandung dalam sejumlah alat tradisional suku Bugis 
memiliki relevansi dengan konten pembelajaran matematika pada pendidikan formal sekolah dasar.

\section{UCAPAN TERIMA KASIH}

Peneliti mengucapkan banyak terima kasih kepada Rektor Universitas Sawerigading Makassar, Ketua LPPM Universitas Sawerigading Makassar, serta masyarakat petani di Kelurahan Tonyamang Kabupaten Pinrang yang telah bekerja sama dengan peneliti dan meluangkan waktu untuk diwawancarai terkait alat-alat pertanian tradisional suku Bugis.

\section{DAFTAR PUSTAKA}

Adam, S. (2004). Ethnomathematical Ideas in the Curriculum. Mathematics Education Research Journal, 16(2), 49-68.

Akbar, A., \& Haidar, I. (2019). Profil Literasi Matematika Ditinjau Dari Gaya Kognitif. Prosiding SNPMATH 2019: Matematika Dalam Era Revolusi Industri 4.0, 3747.

Nurbianti K,N., Kadir, \& Fahinu. (2009). Eksplorasi Konsep Etnomatematika Geometri dalam Permainan Tradisional Anak Masyarakat Poogalampa Buton Selatan. Jurnal Pembelajaran Berpikir Matematika, 4(2), 191-196. DOI: http://dx.doi.org/10.33772/jpbm.v4i2 .8788 .

Barta, J., \& Shockey, T. (2006). The Mathematical Ways of an Aboriginal People: The Norten Ute. The Journal of Mathematics and Culture, 1(1), 79-89.

D’Ambrosio, U. (2001). In My Opinion: What Is Ethnomathematics, and How Can It Help Children in Schools? Teaching Children Mathematics, 7(6), 308-310. https://doi.org/10.5951/tcm.7.6.0308
Yanti, D., Wahyu Widada, M. F. S. (2018). Implementation of Lesson Study to Increase of Mathematical Problem Solving Ability and Mathematical

Communication Ability for Students Teacher Prospective of Mathematics Education Semester III University of Bengkulu . International Journal of Science and Research (IJSR), 7(1), 2001-2006.

https://doi.org/10.21275/ART201798 54

Entremont, Y. (2015). Linking mathematics , culture and community. Procedia Social and Behavioral Sciences, 174(1999), 2818-2824. https://doi.org/10.1016/j.sbspro.2015. 01.973

Rosa, M., \& Orey, D. C. (2003). Vinho e Queijo: Etnomatemática e Modelagem! [Wine and cheese: Ethnomathematics and modelling. BOLEMA, 16(20), 1-16.

Sylviyani, H., (2017). Etnomatematika: Aplikasi Bangun Datar Segiempat pada Candi Muaro Jambi. Jurnal Aksioma, 8(2), 99-110.

Harding-dekam, J. L. (2007). Foundations in ethnomathematics for prospective elementary teachers. Journal of Mathematics and Culture, 1(2), 119.

Latif, Y. (2020). Pendidikan yang Brkebudayaan: Histori, Konsepsi, dan Aktualisasi Pendidikan Transformatif. Jakarta: PT Gramedia Pustaka Utama.

Permendiknas Nomor 22 Tahun 2006 Tentang Standar Isi. Jakarta: Kemdikbud.

Orey, D. C., \& Rosa, M. (2006). Ethnomathematics: Cultural Assertions and Challenges Towards Pedagogical Action. The Journal of 
Mathematics and Culture, 6(1), 5778.

Rosa, M., \& Clark, D. (2011). Ethnomathematics: the cultural aspects of mathematics. Revista Latinoamericana

Etnomatemática, 4(2), 32-54.

Side, S., Sukarna, S., \& Jusriadi, J. (2020). Analisis Matematika Pada Pembuatan Rumah Panggung Toraja. Journa of Mathematics,
Computations, and Statistics, 3(1), 1-10.

DOI: https://doi.org/10.35580/jmathcos.v3i 1. 19179.

Yanti, N. R., Kadir, \& Jafar. (2019). Mathematical Concept of Installing the Support Pole of a Muna Traditional House. Jurnal Pembelajaran Berpikir Matematika, 3(2), 65-72. DOI: http://dx.doi.org/10.33772/jpbm.v3i2 .5 